\title{
Adrenergic Blockade Alters Glucose Kinetics during Exercise in Insulin-dependent Diabetics
}

\author{
Donald C. Simonson, Veikko Koivisto, Robert S. Sherwin, \\ Eleuterio Ferrannini, Rosa Hendler, \\ Anders Juhlin-Dannfelt, and Ralph A. DeFronzo \\ Department of Internal Medicine, Yale University School of \\ Medicine, New Haven, Connecticut 06510
}

A

bstract. We investigated the effects of alpha and/or beta adrenergic blockade (with phentolamine and/or propranolol) on glucose homeostasis during exercise in six normal subjects and in seven Type I diabetic subjects. The diabetics received a low dose insulin infusion $(0.07 \mathrm{mU} / \mathrm{kg} \cdot \mathrm{min})$ designed to maintain plasma glucose at $\sim 150 \mathrm{mg} / \mathrm{dl}$. In normals, neither alpha, beta, nor combined alpha and beta adrenergic blockade altered glucose production, glucose uptake, or plasma glucose concentration during exercise. In diabetics, exercise alone produced a decline in glucose concentration from 144 to $116 \mathrm{mg} / \mathrm{dl}$. This was due to a slightly diminished rise in hepatic glucose production in association with a normal increase in glucose uptake. When exercise was performed during beta adrenergic blockade, the decline in plasma glucose was accentuated. An exogenous glucose infusion $(2.58 \mathrm{mg} / \mathrm{kg} \cdot \mathrm{min})$ was required to prevent glucose levels from falling below $90 \mathrm{mg} / \mathrm{dl}$. The effect of beta blockade was accounted for by a blunted rise in hepatic glucose production and an augmented rise in glucose utilization. These alterations were unrelated to changes in plasma insulin and glucagon levels, which were similar in the presence and absence of propranolol. In contrast, when the diabetics exercised during alpha adrenergic blockade, plasma glucose concentration rose from 150 to 164 $\mathrm{mg} / \mathrm{dl}$. This was due to a significant increase in hepatic glucose production and a small decline in exercise-induced glucose utilization. These alterations also could not be explained by differences in insulin and glucagon levels.

We conclude that the glucose homeostatic response

Received for publication 1 December 1982 and in revised form 2 February 1984.

J. Clin. Invest.

(C) The American Society for Clinical Investigation, Inc. 0021-9738/84/06/1648/11 $\$ 1.00$

Volume 73, June 1984, 1648-1658 to exercise in insulin-dependent diabetics, in contrast to healthy controls, is critically dependent on the adrenergic nervous system.

\section{Introduction}

During exercise, an increase in hepatic glucose production is essential to meet the increased glucose requirements of the working muscle and to prevent hypoglycemia (1-3). However, the precise mechanisms underlying this delicate balance between glucose production and glucose uptake by peripheral tissues remain unclear. Previous studies have focused on the importance of hormonal changes in mediating the response of the liver, particularly the fall in insulin $(4,5)$ and rise in glucagon concentrations $(5,6)$. These studies have yielded apparently conflicting results. While it has been suggested that the decrease in insulin secretion is important in promoting glucose production or in sensitizing the liver to the stimulatory effects of counterregulatory hormones (4), it has been demonstrated that hypoinsulinemia is not required for exercise to cause a rise in hepatic glucose production (5). Similarly, an increase in glucagon was found to be crucial for the hepatic response to exercise by some investigators (6), but not by others (5). Studies in the pancreatectomized diabetic dog suggest that additional factors must be considered (7). Under these conditions, exercise evoked a normal increase in hepatic glucose production, even though circulating insulin and glucagon concentrations remained constant.

The role of catecholamines in regulating glucose metabolism during exercise has been investigated by using adrenergic blocking agents. When exercise is performed during propranolol infusion, hepatic glucose production is not suppressed either in the $\operatorname{dog}(8)$ or in humans $(9,10)$. Nevertheless, in some instances, plasma glucose declines due to an acceleration of glucose utilization. The influence of alpha blockade has been more difficult to assess because of its propensity to cause orthostatic hypotension. In the running dog, phentolamine infusion diminishes the exercise-induced increase in glucose uptake (8), while in exercising man, phentolamine produces impaired glucose utilization despite the lack of suppression of plasma insulin levels 
(11). However, it is unclear whether such changes are due to alpha blockade or a reduction in exercise intensity. Likewise, the apparent lack of effect of beta blockade on exercise-induced hepatic glucose production may conceivably be due to the inhibition of insulin secretion induced by unopposed alpha adrenergic stimulation.

It is not known whether the hepatic response to exercise in Type I diabetics is more dependent on the exercise-stimulated release of catecholamines. However, several lines of evidence are in keeping with this possibility. Insulin-treated diabetics exhibit an exaggerated rise in blood glucose during physiological epinephrine infusion as a result of an excessive increase in hepatic glucose production $(12,13)$. Of particular importance, this effect is more readily suppressed by beta blockade in the diabetic as compared with normal subjects (14). In addition, the inability of such patients to reduce circulating insulin levels during exercise and propranolol infusion may make them more susceptible to blockade of their hepatic beta adrenergic receptors. Several recent reports have suggested that beta adrenergic blockade may result in clinically significant hypoglycemia in diabetics $(15-17)$ as well as nondiabetic individuals $(15,16,18)$.

The present study was consequently undertaken to contrast the effects of alpha and beta adrenergic blockade (with phentolamine and propranolol, respectively) in normal and Type I diabetic subjects during moderate exercise. To ensure that the exercise stimulus remained constant during alpha adrenergic blockade, all studies were performed in the supine position using a bicycle ergometer at a constant percentage of each subject's maximum work capacity.

\section{Methods}

Subjects. Six healthy young normal controls and seven insulin-dependent (Type I, juvenile onset) diabetics were studied. The control group consisted of three males and three females (mean age, $26 \pm 2 \mathrm{yr}$ ) who were within $15 \%$ of ideal body weight (mean $=106 \pm 6 \%$ based on medium frame individuals from the Metropolitan Life Insurance Tables, 1959). The Type I diabetic group consisted of six males and one female (mean age, $24 \pm 2 \mathrm{yr}$ ) who were $101 \pm 3 \%$ of ideal body weight. They had no evidence of hepatic, renal, cardiovascular, or other endocrine disease and none were taking any medications other than insulin. The insulin dose in the Type I diabetics averaged $47 \pm 8$ units/day. All subjects consumed a weight-maintaining diet containing at least $200 \mathrm{~g}$ of carbohydrate/d for $3 \mathrm{~d}$ prior to study. The purpose, nature, and potential risks of the study were explained to each subject before obtaining his/ her voluntary informed written consent. The experimental protocol was reviewed and approved by the Human Investigation Committee of Yale University School of Medicine.

Experimental protocol. Each subject initially underwent a measurement of maximal aerobic capacity $\left(\dot{\mathrm{V}}_{2} \max \right)^{1}$ on a bicycle ergometer. Mean maximal oxygen consumption for the normal $(39 \pm 4 \mathrm{ml} / \mathrm{kg} \cdot \mathrm{min})$ and diabetic $(38 \pm 4 \mathrm{ml} / \mathrm{kg} \cdot \mathrm{min})$ groups were comparable, indicating a similar degree of physical fitness in the two groups.

1. Abbreviations used in this paper: $\mathrm{Ra}$, rate of glucose production; $\mathrm{Rd}$, rate of glucose utilization; $\mathrm{vO}_{2}$ max, maximal aerobic capacity.
All studies in normals and diabetics were begun at $0800 \mathrm{~h}$ after a 10-12-h overnight fast. Exercise was performed in the supine position using a bicycle ergometer. The intensity of exercise was adjusted to $40 \%$ of each subject's $\dot{\mathrm{V}}_{2}$ max. The control subjects participated in the four protocols as outlined below. Studies were performed in randomized order at 4-10-d intervals.

Protocol I: exercise alone. Subjects exercised for $40 \mathrm{~min}$ and this was followed by a 30 -min recovery period.

Protocol II: exercise plus propranolol. $30 \mathrm{~min}$ prior to exercise, a bolus of propranolol ( $200 \mu \mathrm{g} / \mathrm{kg}$; Inderal, Ayerst Laboratories, New York) was given intravenously over a period of $20 \mathrm{~min}$. This was followed by a continuous infusion of propranolol at a rate of $80 \mu \mathrm{g} / \mathrm{min}$ during the last $10 \mathrm{~min}$ of the base-line period, and throughout the 40 -min exercise and the 30-min recovery periods.

Protocol III: exercise plus phentolamine. $30 \mathrm{~min}$ before exercise, a bolus of phentolamine ( $70 \mu \mathrm{g} / \mathrm{kg}$; Regitine, Ciba-Geigy Co., Summit, $\mathrm{NJ}$ ) was given by intravenous push. This was immediately followed by a continuous infusion at a rate of $7 \mu \mathrm{g} / \mathrm{kg} \cdot \mathrm{min}$ throughout the 30 -min basal period, the $40 \mathrm{~min}$ of exercise, and the 30 -min recovery period.

Protocol IV: exercise plus propranolol and phentolamine. Starting $30 \mathrm{~min}$ prior to exercise and continuing throughout the exercise and recovery periods, infusions of propranolol and phentolamine were given as described above.

The Type I diabetics participated only in Protocols I-III. Their last insulin dose (Lente or NPH) was $24 \mathrm{~h}$ prior to study. On the morning of study, they received a continuous infusion of regular insulin. The initial insulin infusion rate for each subject was chosen empirically and did not exceed $0.11 \mathrm{mU} / \mathrm{kg} \cdot \mathrm{min}$. This dose is within the normal range of basal insulin requirements for insulin-dependent diabetics. The initial insulin infusion was subsequently adjusted to achieve a constant level of glycemia of $\sim 150 \mathrm{mg} / \mathrm{dl}$. In all diabetic subjects, the plasma glucose concentration was constant for at least $30 \mathrm{~min}$ prior to the start of exercise or the infusion of propranolol or phentolamine. Once constancy of glycemia was attained, the insulin infusion rate was not changed during the remainder of the study. The mean insulin infusion rate was $0.07 \pm 0.01$ (range, $0.04-0.11$ ) $\mathrm{mU} / \mathrm{kg} \cdot \mathrm{min}$. Each patient received the same rate of insulin infusion in each of the three studies (control, propranolol, and phentolamine) in which he participated. Control subjects received a saline infusion during the interval that the diabetics were receiving an insulin infusion.

Prior to the start of exercise, each subject's glucose pool was labeled with 3-[3 H]glucose (New England Nuclear, Boston, MA) to allow determination of rates of endogenous glucose appearance (primarily from the liver) and glucose disappearance. In the controls, the tritiated glucose was administered as a priming dose of $25 \mu \mathrm{Ci}$ followed by a continuous infusion of $0.25 \mu \mathrm{Ci} / \mathrm{min}$ for $120 \mathrm{~min}$ before the start of exercise (Protocol I) or propranolol and/or phentolamine (Protocols II-IV). In the insulindependent diabetics, the priming dose of $3-\left[{ }^{3} \mathrm{H}\right]$ glucose was increased in proportion to the increase in fasting glucose concentration, and the continuous infusion was administered for $180 \mathrm{~min}$ before exercise (Protocol I) or propranolol or phentolamine (Protocols II and III) to allow adequate time for equilibration with the glucose pool. Previous studies by Sacca et al. (19) have shown that tritiated glucose infusion in the fasted state does not result in significant labeling of liver glycogen. In all studies, the $3-\left[{ }^{3} \mathrm{H}\right]$ glucose infusion was continued throughout the exercise and recovery periods. Plasma samples for determination of glucose specific activity were obtained every $5 \mathrm{~min}$ during the last 30 min of the equilibration period, during exercise, and during recovery.

Calculations. The rates of glucose production $(\mathrm{Ra})$ and glucose utilization (Rd) were calculated from the equations of Steele et al. (20) in 
their derivative form using a value of 0.65 for the pool fraction. During the exercise plus propranolol study in the diabetics, it was necessary to infuse exogenous glucose at a rate of $2.58 \mathrm{mg} / \mathrm{kg} \cdot \min$ to prevent severe hypoglycemia. Thus, during this study protocol, endogenous glucose production was calculated by subtracting the exogenous glucose infusion rate from the total $\mathrm{Ra}$ as determined by the tracer technique.

Analyses. Plasma glucose levels were measured by using the glucose oxidase method (Glucostat, Beckman Instruments Inc., Fullerton, CA). Methods for the determination of $3-\left[{ }^{3} \mathrm{H}\right]$ glucose specific activity have been published previously (21). Plasma insulin concentration in the controls was determined by standard radioimmunoassay procedures using talc to separate bound from free insulin (22). In the diabetic subjects, immunoreactive free insulin concentration was determined by immediately treating freshly drawn plasma with polyethylene glycol to precipitate insulin antibodies (23). Free insulin recovery in normal subjects determined after the addition of PEG averaged $98 \pm 4 \%$ of the values determined directly by radioimmunoassay (24). C-peptide levels were determined by radioimmunoassay (Byk-Mallinckrodt Radiopharmaceuticals, Dietzenbach, West Germany). Samples for epinephrine and norepinephrine were collected in glutathione and subsequently analyzed by the radioenzymatic method (Cat-a-Kit, Upjohn Co., Kalamazoo, MI). Plasma glucagon concentration was determined by radioimmunoassay using the 30,000 antibody of Aguilar-Parada et al. (25). Plasma free fatty acid levels were determined by the method of Dole (26) as modified by Novak (27).

Statistics. All data are expressed as the mean \pm SEM. Statistical comparisons were made using Student's $t$ test for paired analysis.

\section{Results}

Normal controls-glucose kinetics (Table I and Figs. 1 A and $B$ )

Protocol I: exercise alone. With the onset of exercise, basal glucose uptake $(2.17 \pm 0.16 \mathrm{mg} / \mathrm{kg} \cdot \mathrm{min})$ increased promptly reaching a maximum of $3.49 \pm 0.43 \mathrm{mg} / \mathrm{kg} \cdot \min$ after $40 \mathrm{~min}$ and then returned to basal levels $(2.11 \pm 0.14 \mathrm{mg} / \mathrm{kg} \cdot \mathrm{min})$ by the end of the 30-min recovery period (Fig. $1 \mathrm{~A}$ ). The rise in glucose utilization during exercise was closely paralleled by an increase in hepatic glucose production, and plasma glucose concentration remained constant (Fig. 1 B). Following exercise, glucose production fell in concert with the fall in glucose utilization and the plasma glucose concentration remained unchanged.

Protocol II: exercise plus propranolol. Basal hepatic glucose production and glucose utilization were not significantly altered during the 30-min period of propranolol infusion (immediately prior to the onset of exercise). Following exercise, the rise in glucose utilization $(4.30 \pm 0.34 \mathrm{mg} / \mathrm{kg} \cdot \mathrm{min})$ was slighlty, although not significantly, greater than during the control study when exercise was performed without propranolol $(3.49 \pm 0.43$ $\mathrm{mg} / \mathrm{kg} \cdot \mathrm{min}, P=0.10$ ). However, the rise in glucose uptake was closely matched by an increase in hepatic glucose production $(4.54 \pm 0.33 \mathrm{mg} / \mathrm{kg} \cdot \mathrm{min})$ and plasma glucose concentration was

Table I. Effects of Alpha and Beta Adrenergic Blockade on Glucose Kinetics during Exercise in Normal Subjects

\begin{tabular}{|c|c|c|c|c|}
\hline \multirow[b]{2}{*}{ Group } & \multicolumn{4}{|l|}{ Study period } \\
\hline & Basal & Pre-exercise & Exercise & Recovery \\
\hline \multicolumn{5}{|l|}{ Control } \\
\hline $\mathrm{Ra}(\mathrm{mg} / \mathrm{kg} \cdot \min )$ & $2.17 \pm 0.16$ & & $3.49 \pm 0.30 \ddagger$ & $2.26 \pm 0.17$ \\
\hline $\mathrm{Rd}(m g / k g \cdot \min )$ & $2.17 \pm 0.16$ & & $3.49 \pm 0.43^{*}$ & $2.11 \pm 0.14$ \\
\hline Glucose $(m g / d l)$ & $88 \pm 2$ & & $89 \pm 3$ & $90 \pm 3$ \\
\hline \multicolumn{5}{|c|}{ Propranolol and/or phentolamine infusion } \\
\hline \multicolumn{5}{|l|}{ Propranolol } \\
\hline $\mathbf{R a}$ & $2.14 \pm 0.16$ & $2.06 \pm 0.22$ & $4.54 \pm 0.33 \ddagger$ & $2.00 \pm 0.20$ \\
\hline $\mathbf{R d}$ & $2.14 \pm 0.16$ & $1.99 \pm 0.23$ & $4.30 \pm 0.34 \ddagger$ & $2.40 \pm 0.23$ \\
\hline Glucose & $90 \pm 2$ & $91 \pm 2$ & $90 \pm 2$ & $89 \pm 3$ \\
\hline \multicolumn{5}{|l|}{ Phentolamine } \\
\hline $\mathbf{R a}$ & $2.15 \pm 0.14$ & $1.47 \pm 0.19^{*}$ & $3.33 \pm 0.32 \ddagger$ & $1.96 \pm 0.32$ \\
\hline Rd & $2.15 \pm 0.14$ & $1.63 \pm 0.15^{*}$ & $3.38 \pm 0.38^{*}$ & $1.82 \pm 0.35$ \\
\hline Glucose & $88 \pm 3$ & $86 \pm 4$ & $84 \pm 5$ & $84 \pm 4$ \\
\hline \multicolumn{5}{|c|}{ Propranolol + Phentolamine } \\
\hline $\mathbf{R a}$ & $2.19 \pm 0.08$ & $1.80 \pm 0.15$ & $4.17 \pm 0.37 \ddagger$ & $2.20 \pm 0.21$ \\
\hline $\mathbf{R d}$ & $2.19 \pm 0.08$ & $1.84 \pm 0.16$ & $4.12 \pm 0.41 \ddagger$ & $2.03 \pm 0.20$ \\
\hline Glucose & $89 \pm 3$ & $88 \pm 4$ & $82 \pm 2^{*}$ & $84 \pm 2$ \\
\hline
\end{tabular}

Plasma glucose concentration, $\mathrm{Ra}$, and $\mathrm{Rd}$ are shown during the basal state, the pre-exercise infusion period, at the end of 40 min of exercise, and at the end of the 30 -min recovery period. All results are expressed as the mean \pm SEM. $(*, P<0.05$ vs. basal; $¥, P<0.01$ vs. basal). 

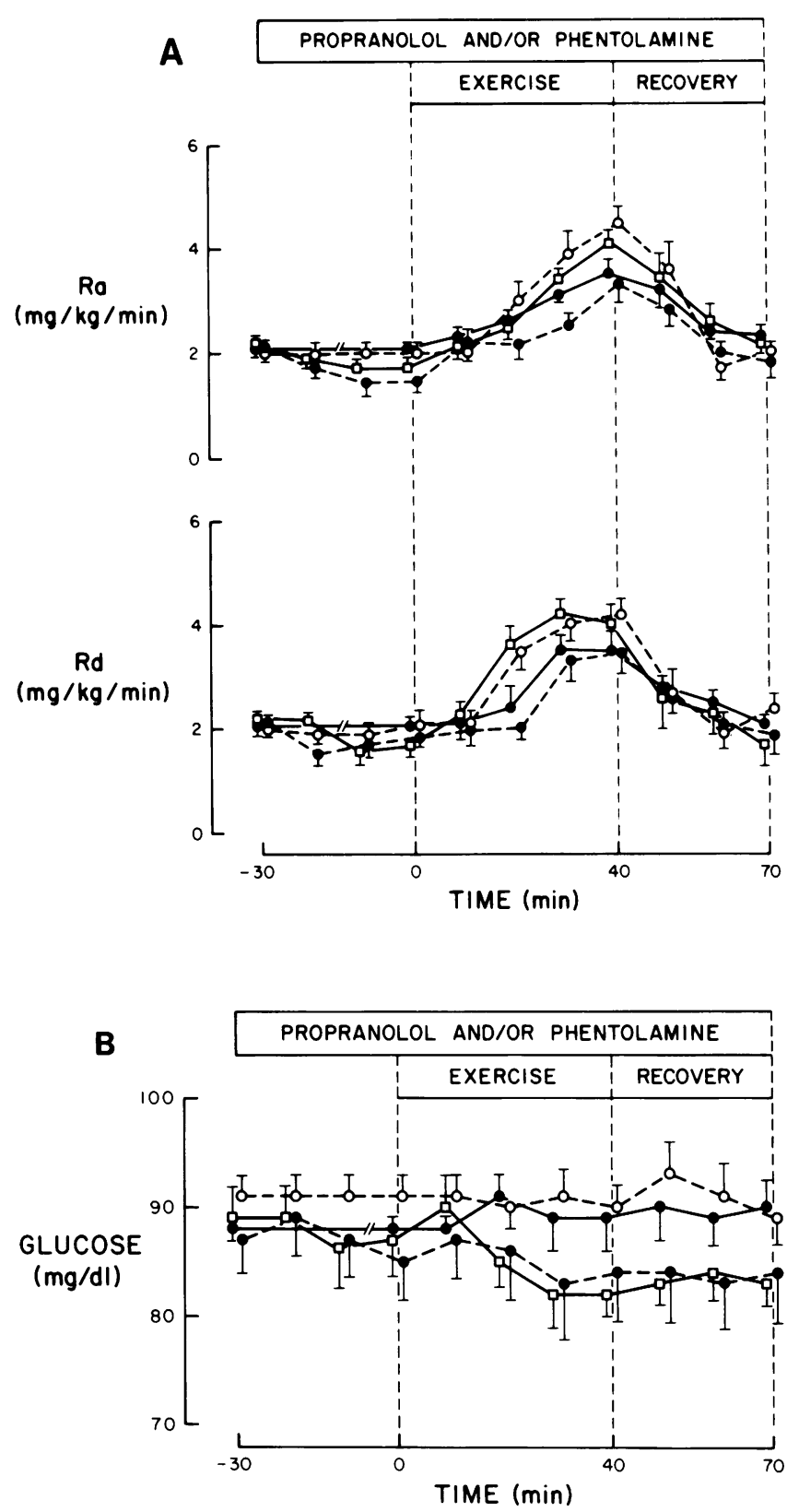

Figure 1. (A) Effect of alpha and beta adrenergic blockade on glucose kinetics during exercise in normal subjects. Changes in hepatic glucose production $(\mathrm{Ra})$ and glucose utilization $(\mathrm{Rd})$ are shown during 40 min of submaximal exercise $\left(40 \%\right.$ of $\mathrm{VO}_{2}$ max) followed by a 30 min recovery period. $(B)$ Effect of alpha and beta adrenergic blockade on plasma glucose concentration during exercise in normal subjects. Control, —- -; propranolol, -- - $0---$; phentolamine,

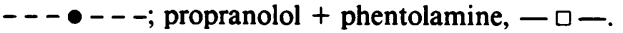

unchanged (Table I). During the recovery period, both glucose utilization and glucose production returned to base-line values and plasma glucose levels were unchanged.
Protocol III: exercise plus phentolamine. During the 30-min period of phentolamine infusion (just prior to exercise), basal glucose utilization and production $(2.15 \pm 0.14 \mathrm{mg} / \mathrm{kg} \cdot \mathrm{min}) \mathrm{de}-$ clined significantly $(P<0.05$ vs. basal). Nevertheless, the changes in glucose utilization and glucose production both during exercise and in the recovery period were similar to those observed with exercise alone, and therefore, glucose concentration remained unchanged.

Protocol IV: exercise plus propranolol and phentolamine. Combined beta and alpha adrenergic blockade produced a small and statistically insignificant decline in basal glucose utilization and production in the 30 -min period before exercise (Table I). During exercise, the increase in glucose utilization (to $4.12 \pm 0.41$ $\mathrm{mg} / \mathrm{kg} \cdot \mathrm{min}$ ) was slightly, although not significantly, greater than with exercise alone. The rise in hepatic glucose production lagged slightly behind the increase in glucose utilization and a small, but statistically significant, decline in plasma glucose concentration was observed $(P<0.05$ vs. basal). During the recovery period, both glucose utilization and production returned toward basal values.

\section{Normal controls-hormonal and free fatty acid response (Table II)}

Insulin and C-peptide. During exercise alone, plasma insulin exhibited a small and statistically insignificant decline from $16 \pm 2$ to $13 \pm 2 \mu \mathrm{U} / \mathrm{ml}$ and there was no significant change in plasma C-peptide concentration. While propranolol did not significantly affect the plasma insulin or C-peptide response to exercise, alpha blockade with phentolamine produced a $40 \%$ rise in circulating insulin before exercise $(P<0.01$ vs. basal) and a further $30 \%$ increase at the end of $40 \mathrm{~min}$ of exercise $(P<0.01 \mathrm{vs}$. basal). This was accompanied by a small but statistically insignificant rise in C-peptide from 0.46 to $0.57 \mathrm{ng} / \mathrm{ml}$ during exercise. When propranolol and phentolamine were infused together, plasma insulin and C-peptide did not change from base line during either the exercise or recovery periods.

Glucagon. Plasma glucagon concentration did not change during exercise alone. Furthermore, neither alpha, beta, nor alpha and beta blockade in combination with exercise produced any significant change in circulating glucagon levels.

Catecholamines. During exercise alone, plasma epinephrine rose from $22 \pm 5$ to $54 \pm 9 \mathrm{pg} / \mathrm{ml}$ ( $P<0.05$ vs. basal). The rise in plasma epinephrine concentration was slightly, although not significantly, greater when exercise was performed with either propranolol alone or phentolamine alone. During combined alpha and beta blockade, plasma epinephrine increased sixfold (to $223 \pm 81 \mathrm{pg} / \mathrm{ml}$ ) above basal levels. Because of the large variation in individual responses, however, this increase did not reach statistical significance ( $P=0.13$ vs. basal).

During exercise, plasma norepinephrine concentration rose from $218 \pm 40$ to $365 \pm 67 \mathrm{pg} / \mathrm{ml}$. The increase in norepinephrine was greater when exercise was performed with either beta adrenergic blockade ( $758 \pm 143 \mathrm{pg} / \mathrm{ml} ; P<0.05$ vs. basal) or alpha adrenergic blockade $(1603 \pm 229 \mathrm{pg} / \mathrm{ml} ; P<0.01$ vs. basal). The greatest rise in norepinephrine $(1938 \pm 399 \mathrm{pg} / \mathrm{ml} ; P<0.05$ vs. 
Table II. Effects of Alpha and Beta Adrenergic Blockade on the Hormonal Response to Exercise in Normal Subjects

\begin{tabular}{|c|c|c|c|c|}
\hline \multirow[b]{2}{*}{ Group } & \multicolumn{4}{|l|}{ Study period } \\
\hline & Basal & Pre-exercise & Exercise & Recovery \\
\hline \multicolumn{5}{|l|}{ Control } \\
\hline Insulin $(\mu U / m l)$ & $16 \pm 2$ & & $13 \pm 2$ & $19 \pm 2 \ddagger$ \\
\hline C-peptide $(n g / m l)$ & $0.37 \pm 0.02$ & & $0.37 \pm 0.04$ & $0.37 \pm 0.02$ \\
\hline Glucagon $(p g / m l)$ & $64 \pm 16$ & & $69 \pm 17$ & $69 \pm 18$ \\
\hline Epi $(p g / m l)$ & $22 \pm 5$ & & $54 \pm 9^{*}$ & $44 \pm 9$ \\
\hline $\mathrm{NE}(p g / m l)$ & $218 \pm 40$ & & $365 \pm 67^{*}$ & $296 \pm 54$ \\
\hline FFA $(\mu \mathrm{mol} /$ liter $)$ & $556 \pm 126$ & & $537 \pm 156$ & $561 \pm 148$ \\
\hline \multicolumn{5}{|c|}{ Propranolol and/or phentolamine infusion } \\
\hline \multicolumn{5}{|l|}{ Propranolol } \\
\hline Insulin & $13 \pm 2$ & $14 \pm 2$ & $10 \pm 2$ & $17 \pm 3$ \\
\hline C-peptide & $0.42 \pm 0.02$ & $0.41 \pm 0.03$ & $0.38 \pm 0.03$ & $0.44 \pm 0.04$ \\
\hline Glucagon & $66 \pm 19$ & $64 \pm 17$ & $59 \pm 15$ & $76 \pm 15$ \\
\hline Epi & $20 \pm 5$ & $27 \pm 8$ & $90 \pm 16 \ddagger$ & $37 \pm 7$ \\
\hline NE & $265 \pm 46$ & $314 \pm 67$ & $758 \pm 143^{*}$ & $310 \pm 34$ \\
\hline FFA & $601 \pm 165$ & $590 \pm 211$ & $496 \pm 189$ & $793 \pm 362$ \\
\hline \multicolumn{5}{|l|}{ Phentolamine } \\
\hline Insulin & $12 \pm 2$ & $17 \pm 2 \ddagger$ & $22 \pm 3 \ddagger$ & $20 \pm 2 \ddagger$ \\
\hline C-peptide & $0.46 \pm 0.09$ & $0.51 \pm 0.13$ & $0.57 \pm 0.14$ & $0.47 \pm 0.06$ \\
\hline Glucagon & $72 \pm 24$ & $76 \pm 26$ & $85 \pm 26$ & $80 \pm 25$ \\
\hline Epi & $26 \pm 8$ & $32 \pm 9$ & $92 \pm 13 \ddagger$ & $49 \pm 4$ \\
\hline NE & $340 \pm 60$ & $782 \pm 123 \ddagger$ & $1603 \pm 229 \ddagger$ & $868 \pm 245$ \\
\hline FFA & $608 \pm 99$ & $880 \pm 105 \ddagger$ & $1037 \pm 129 \ddagger$ & $985 \pm 122$ \\
\hline \multicolumn{5}{|c|}{ Propranolol + Phentolamine } \\
\hline Insulin & $16 \pm 2$ & $17 \pm 2$ & $15 \pm 3$ & $17 \pm 3$ \\
\hline C-peptide & $0.42 \pm 0.03$ & $0.50 \pm 0.07$ & $0.43 \pm 0.05$ & $0.41 \pm 0.05$ \\
\hline Glucagon & $86 \pm 35$ & $78 \pm 32$ & $77 \pm 33$ & $90 \pm 40$ \\
\hline Epi & $37 \pm 4$ & $50 \pm 4^{*}$ & $223 \pm 81$ & $228 \pm 125$ \\
\hline $\mathrm{NE}$ & $292 \pm 36$ & $720 \pm 114 \ddagger$ & $1938 \pm 399 * \S$ & $1065 \pm 218^{*} \S$ \\
\hline FFA & $529 \pm 91$ & $580 \pm 127$ & $475 \pm 117$ & $684 \pm 148$ \\
\hline
\end{tabular}

Plasma insulin, glucagon, epinephrine (Epi), norepinephrine (NE), and free fatty acid (FFA) levels are shown during the basal state, the preexercise infusion period, during $40 \mathrm{~min}$ of exercise, and at the end of the $30 \mathrm{~min}$ recovery period. All results are expressed as the mean $\pm \mathrm{SEM}$. $\left(^{*}, P<0.05\right.$ vs. basal; $\ddagger, P<0.01$ vs. basal; $\S, P<0.05$ vs. control; ", $P<0.01$ vs. control).

basal) was observed when exercise was performed with combined alpha and beta adrenergic blockade.

Free fatty acids. Basal free fatty acid concentration (556 \pm 126 $\mu \mathrm{mol} / \mathrm{liter}$ ) remained unchanged during exercise alone. In the presence of propranolol, a small, albeit insignificant, decline in plasma free fatty acid concentration occurred during exercise. Conversely, phentolamine infusion produced a significant rise in free fatty acids prior to exercise $(880 \pm 105 \mu \mathrm{mol} / \mathrm{liter} ; P$ $<0.01)$ and this was followed by a further significant increase to $1037 \pm 129 \mu \mathrm{mol} / \mathrm{liter}(P<0.01)$ during exercise. Combined alpha and beta blockade did not result in any significant change in circulating free fatty acid levels.
Insulin-dependent diabetics-glucose kinetics (Table III, Figs. $2 A$ and $B$ )

Protocol I: exercise alone. In the basal state, plasma glucose concentration averaged $144 \pm 13 \mathrm{mg} / \mathrm{dl}$ (range, $84-179 \mathrm{mg} / \mathrm{dl}$ ). During exercise, glucose levels gradually fell reaching a nadir of $116 \pm 11 \mathrm{mg} / \mathrm{dl}$ after $40 \mathrm{~min}(P<0.05$ vs. basal). Thereafter, glucose concentration remained constant at this level throughout the post-exercise recovery period. The exercise-induced decline in plasma glucose concentration occurred because the increase in glucose uptake $(4.42 \pm 0.40 \mathrm{mg} / \mathrm{kg} \cdot \mathrm{min})$ exceeded the increase in hepatic glucose production $(2.72 \pm 0.41 \mathrm{mg} / \mathrm{kg} \cdot \mathrm{min})$.

Protocol II: exercise plus propranolol. Before exercise, the 
Table III. Effects of Alpha and Beta Adrenergic Blockade on Glucose Kinetics during Exercise in Type I Diabetics

\begin{tabular}{|c|c|c|c|c|}
\hline \multirow[b]{2}{*}{ Group } & \multicolumn{4}{|l|}{ Study period } \\
\hline & Basal & Pre-exercise & Exercise & Recovery \\
\hline \multicolumn{5}{|l|}{ Control } \\
\hline $\mathrm{Ra}(m g / k g \cdot \min )$ & $2.36 \pm 0.12$ & & $2.72 \pm 0.41$ & $1.93 \pm 0.25$ \\
\hline $\mathrm{Rd}(\mathrm{mg} / \mathrm{kg} \cdot \mathrm{min})$ & $2.36 \pm 0.12$ & & $4.42 \pm 0.40 \ddagger$ & $2.05 \pm 0.43$ \\
\hline Glucose $(m g / d l)$ & $144 \pm 13$ & & $116 \pm 11^{*}$ & $113 \pm 13^{*}$ \\
\hline \multicolumn{5}{|c|}{ Propranolol or phentolamine infusion } \\
\hline \multicolumn{5}{|l|}{ Propranolol } \\
\hline $\mathbf{R a}$ & $2.22 \pm 0.14$ & $1.43 \pm 0.14^{*}$ & $1.48 \pm 0.43 \S$ & $1.99 \pm 0.48$ \\
\hline Rd & $2.22 \pm 0.14$ & $1.77 \pm 0.12^{*}$ & $6.30 \pm 0.55 \ddagger \S$ & $2.80 \pm 0.35$ \\
\hline Glucose & $144 \pm 10$ & $140 \pm 10$ & $90 \pm 4 \ddagger \S$ & $100 \pm 6^{*}$ \\
\hline \multicolumn{5}{|l|}{ Phentolamine } \\
\hline $\mathrm{Ra}$ & $2.43 \pm 0.17$ & $1.50 \pm 0.13^{*}$ & $4.88 \pm 0.45 \ddagger \S$ & $2.53 \pm 0.39$ \\
\hline Rd & $2.43 \pm 0.17$ & $1.84 \pm 0.23^{*}$ & $3.93 \pm 0.58^{*}$ & $2.52 \pm 0.10$ \\
\hline Glucose & $150 \pm 10$ & $145 \pm 9$ & $164 \pm 15 \S$ & $169 \pm 19 \S$ \\
\hline
\end{tabular}

Plasma glucose concentration, Ra, and Rd are shown during the basal state, the pre-exercise infusion period, at the end of 40 min of exercise, and at the end of the 30 -min recovery period. All results are expressed as the mean \pm SEM. $\left({ }^{*}, P<0.05\right.$ vs. basal; $\neq, P<0.01$ vs. basal; $\S . P<0.05$ vs. control).

fasting plasma glucose concentration was $144 \pm 10 \mathrm{mg} / \mathrm{dl}$ (range, $91-170 \mathrm{mg} / \mathrm{dl})$. The propranolol infusion produced a fall in both glucose production and glucose uptake $(P<0.05)$; consequently, plasma glucose levels remained relatively stable. When exercise was performed with propranolol, there was a rapid decline in plasma glucose concentration which reached $111 \pm 8$ $\mathrm{mg} / \mathrm{dl}$ after $20 \mathrm{~min}$. To prevent severe hypoglycemia and its accompanying counterregulatory response, exogenous glucose was infused at a rate of up to $2.58 \mathrm{mg} / \mathrm{kg} \cdot \min$ during the last $20 \mathrm{~min}$ of exercise. Despite this exogenous glucose infusion (which was given only during the propranolol study), the plasma glucose continued to decline to $90 \pm 4 \mathrm{mg} / \mathrm{dl}$ by the end of exercise. Furthermore, the glucose infusion was required to maintain glucose levels constant during the recovery period. The decrease in plasma glucose concentration was significantly greater than the control study (exercise alone) at all time points from 20 to $70 \mathrm{~min}$ (Fig. $2 \mathrm{~B}$ ). The precipitous decline in plasma glucose concentration was due to an enhanced rate of glucose uptake $(6.30 \pm 0.55 \mathrm{mg} / \mathrm{kg} \cdot \mathrm{min})$ compared with the control study $(4.42 \pm 0.40 \mathrm{mg} / \mathrm{kg} \cdot \mathrm{min} ; P<0.05)$, and a failure of hepatic glucose production to rise (Fig. $2 A$ ). In fact, hepatic glucose production at the end of exercise $(1.48 \pm 0.43 \mathrm{mg} / \mathrm{kg} \cdot \mathrm{min})$ was reduced as compared with the basal rate of $2.22 \pm 0.14$ $\mathrm{mg} / \mathrm{kg} \cdot \min (P=0.08)$.

Protocol III: exercise plus phentolamine. As with propranolol, alpha blockade produced a decline in glucose production and glucose uptake in the period prior to exercise, but no change in glucose concentration. When exercise was performed with phentolamine, plasma glucose rose from $150 \pm 10$ (range, $124-170 \mathrm{mg} / \mathrm{dl}$ ) to $164 \pm 15 \mathrm{mg} / \mathrm{dl}$ at the end of exercise and remained significantly elevated throughout the recovery period $(P<0.05$ vs. exercise alone from 30 to $70 \mathrm{~min}$; Fig. $2 \mathrm{~B})$. The rise in plasma glucose concentration was primarily the result of a more pronounced increase in hepatic glucose production $(4.88 \pm 0.45$ vs. $2.72 \pm 0.41 \mathrm{mg} / \mathrm{kg} \cdot$ min during exercise alone, $P$ $<0.05)$. The increase in glucose uptake $(3.93 \pm 0.58 \mathrm{mg} / \mathrm{kg} \cdot \mathrm{min})$ was slightly, although not significantly, less than during exercise alone $(4.42 \pm 0.40 \mathrm{mg} / \mathrm{kg} \cdot \mathrm{min})$.

\section{Insulin-dependent diabetics-hormonal and free fatty acid} response (Table IV)

Insulin and C-peptide. As expected, basal plasma free insulin and C-peptide levels were similar in all three studies and remained unchanged during the exercise and post-exercise recovery periods.

Glucagon. Basal plasma glucagon levels were also similar in all three studies and remained unchanged during exercise or the recovery period. Although glucagon levels tended to increase when exercise was performed with phentolamine, these changes did not reach statistical significance.

Catecholamines. With exercise alone, the rise in plasma epinephrine levels $(32 \pm 9$ to $57 \pm 11 \mathrm{pg} / \mathrm{ml})$ was similar to that in nondiabetic subjects. However, when exercise was performed with propranolol, the rise in epinephrine concentration (from $29 \pm 10$ to $180 \pm 58 \mathrm{pg} / \mathrm{ml} ; P<0.05$ ) exceeded that during exercise alone $(P<0.05)$. Similarly, the exercise-induced increase in epinephrine following alpha adrenergic blockade (18 \pm 6 to 

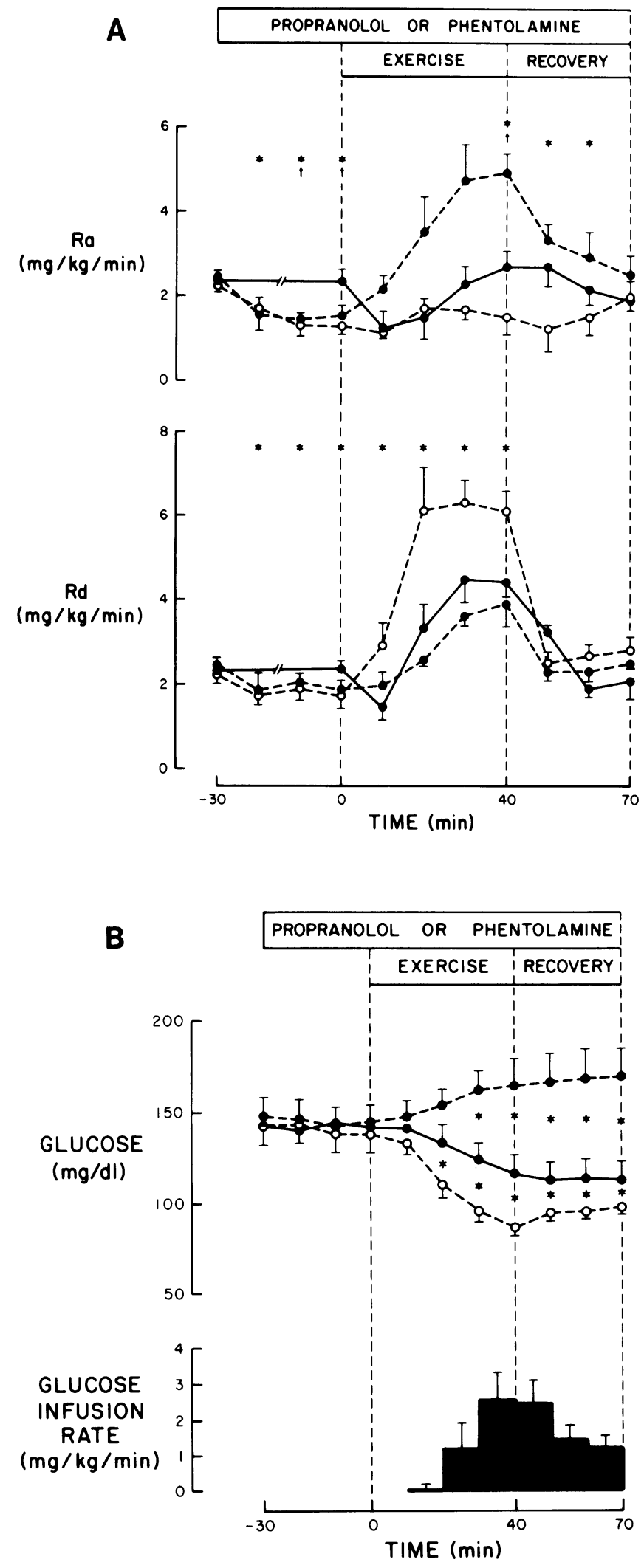

$118 \pm 25 \mathrm{pg} / \mathrm{ml} ; P<0.05)$ was greater than that observed with exercise alone $(P<0.05)$.

Exercise alone produced a slight rise in norepinephrine $(302 \pm 42$ to $442 \pm 64 \mathrm{pg} / \mathrm{ml})$ which was similar to that seen in normals. The exercise-induced rise in norepinephrine during propranolol $(821 \pm 95 \mathrm{pg} / \mathrm{ml} ; P<0.05$ vs. exercise alone) and phentolamine $(1184 \pm 81 \mathrm{pg} / \mathrm{ml} ; P<0.01$ vs. exercise alone) exceeded that during exercise alone, but was similar to the rise observed in nondiabetics.

Free fatty acids. Basal plasma free fatty acid concentration $(465 \pm 150 \mu \mathrm{mol} / \mathrm{liter})$ rose slightly during exercise $(660 \pm 216$ $\mu \mathrm{mol} / \mathrm{liter})$ and continued to rise during the recovery period $(825 \pm 219 \mu \mathrm{mol} /$ liter; $P<0.05$ vs. basal). However, propranolol infusion resulted in a highly significant decline in free fatty acid levels during exercise $(272 \pm 38 \mu \mathrm{mol} /$ liter; $P<0.01$ vs. basal). Conversely, alpha adrenergic blockade with phentolamine resulted in significant elevation of free fatty acids before exercise $(671 \pm 161 \mu \mathrm{mol} / \mathrm{liter} ; P<0.05 \mathrm{vs}$. basal) as well as during exercise (1248 $\pm 312 \mu \mathrm{mol} /$ liter; $P<0.05$ vs. basal).

\section{Discussion}

In the current study, we have examined the effects of alpha and beta adrenergic blockade on the response of hepatic and peripheral tissues to supine exercise in normal and insulin-dependent, Type I diabetic subjects. The study protocol (40 min of supine bicycle exercise at $40 \%$ of $\dot{\mathrm{VO}}_{2}$ max) was designed to represent an exercise stimulus of moderate intensity and duration which would be well within the physical capacity of the individual subjects and would not lead to profound exhaustion. The supine position was used to minimize the effect of alpha blockade on exercise performance and thus provide a uniform exercise stimulus in all experimental groups. In the diabetics, a small amount of insulin $(0.07 \pm 0.01 \mathrm{mU} / \mathrm{kg} \cdot \mathrm{min})$ was infused to maintain the plasma glucose concentration constant and to provide a stable low level of circulating insulin throughout the exercise period $(\sim 15 \mu \mathrm{U} / \mathrm{ml})$.

When the normal control subjects exercised in the absence of adrenergic blockade, circulating epinephrine and norepinephrine levels rose two- to threefold above postabsorptive values and the plasma insulin concentration declined by a small and statistically insignificant amount. Previous studies have suggested that the exercise-induced suppression of insulin is mediated by

Figure 2. (A) Effect of alpha and beta adrenergic blockade on glucose kinetics during exercise in Type I diabetics. Changes in hepatic glucose production $(\mathrm{Ra})$ and glucose utilization $(\mathrm{Rd})$ are shown during 40 min of submaximal exercise $\left(40 \%\right.$ of $\left.\mathrm{VO}_{2} \max \right)$ followed by a 30-min recovery period. ${ }^{*}, P<0.05$ (propranolol vs. control). $\dagger, P$ $<0.05$ (phentolamine vs. control). (B) Effect of alpha and beta adrenergic blockade on plasma glucose concentration during exercise in Type I diabetics. The glucose infusion rate (solid bars) denotes exogenous glucose given only during the propranolol study to prevent hypoglycemia. ${ }^{*}, P<0.05$ vs. control study. Control, $-\bullet-$; propranolol, - - - - - -; phentolamine, - - - --- 
Table IV. Effects of Alpha and Beta Adrenergic Blockade on the Hormonal Response to Exercise in Type I Diabetics

\begin{tabular}{|c|c|c|c|c|}
\hline \multirow[b]{2}{*}{ Group } & \multicolumn{4}{|l|}{ Study period } \\
\hline & Basal & Pre-exercise & Exercise & Recovery \\
\hline \multicolumn{5}{|l|}{ Control } \\
\hline Insulin $(\mu U / m l)$ & $13 \pm 2$ & & $11 \pm 2$ & $11 \pm 3$ \\
\hline C-peptide $(n g / m l)$ & $0.32 \pm 0.06$ & & $0.30 \pm 0.07$ & $0.27 \pm 0.06$ \\
\hline Glucagon $(p g / m l)$ & $92 \pm 19$ & & $91 \pm 17$ & $89 \pm 14$ \\
\hline Epi $(p g / m l)$ & $32 \pm 9$ & & $57 \pm 11 \ddagger$ & $42 \pm 10$ \\
\hline $\mathrm{NE}(\mathrm{pg} / \mathrm{ml})$ & $302 \pm 42$ & & $442 \pm 64$ & $251 \pm 40$ \\
\hline FFA $(\mu \mathrm{mol} /$ liter $)$ & $465 \pm 150$ & & $660 \pm 216$ & $825 \pm 219^{*}$ \\
\hline \multicolumn{5}{|c|}{ Propranolol or phentolamine infusion } \\
\hline \multicolumn{5}{|c|}{ Propranolol } \\
\hline Insulin & $14 \pm 3$ & $15 \pm 4$ & $15 \pm 3$ & $14 \pm 3$ \\
\hline C-peptide & $0.28 \pm 0.06$ & $0.30 \pm 0.06$ & $0.28 \pm 0.06$ & $0.28 \pm 0.06$ \\
\hline Glucagon & $84 \pm 23$ & $82 \pm 20$ & $85 \pm 21$ & $92 \pm 22$ \\
\hline Epi & $29 \pm 10$ & $42 \pm 12^{*}$ & $180 \pm 58 * \S$ & $74 \pm 27$ \\
\hline $\mathrm{NE}$ & $258 \pm 62$ & $300 \pm 79$ & $821 \pm 95 \ddagger \S$ & $300 \pm 22$ \\
\hline FFA & $530 \pm 59$ & $486 \pm 70$ & $272 \pm 38 \ddagger$ & $540 \pm 90$ \\
\hline \multicolumn{5}{|l|}{ Phentolamine } \\
\hline Insulin & $18 \pm 1$ & $20 \pm 3$ & $20 \pm 2$ & $22 \pm 3$ \\
\hline C-peptide & $0.25 \pm 0.06$ & $0.30 \pm 0.08$ & $0.23 \pm 0.07$ & $0.24 \pm 0.07$ \\
\hline Glucagon & $85 \pm 24$ & $86 \pm 16$ & $129 \pm 23$ & $127 \pm 22$ \\
\hline Epi & $18 \pm 6$ & $40 \pm 13^{*}$ & $118 \pm 25 \ddagger \S$ & $60 \pm 12^{*}$ \\
\hline NE & $219 \pm 27$ & $406 \pm 70^{*}$ & $1184 \pm 81 \ddagger^{\prime \prime}$ & $550 \pm 62 \ddagger^{\prime \prime}$ \\
\hline FFA & $462 \pm 154$ & $671 \pm 161^{*}$ & $1248 \pm 312 * \S$ & $1194 \pm 339$ \\
\hline
\end{tabular}

Plasma insulin, glucagon, epinephrine (Epi), norepinephrine (NE), and free fatty acid (FFA) levels are shown during the basal state, the preexercise infusion period, during $40 \mathrm{~min}$ of exercise, and at the end of the $30 \mathrm{~min}$ recovery period. All results are expressed as the mean \pm SEM. ( ${ }^{*}, P<0.05$ vs. basal; $\ddagger, P<0.01$ vs. basal; $\S . P<0.05$ vs. control; ", $P<0.01$ vs. control).

alpha adrenergic stimulation of the pancreatic beta cell $(11,28$, $29)$ and that it may provide a means of enhancing hepatic sensitivity to the action of counterregulatory hormones (4). However, significant suppression of insulin secretion is most consistently observed only during prolonged or strenuous exercise $(3,4,11,28)$ and may not be present during shorter and less intense periods of exercise (3). No change was observed in the circulating plasma glucagon concentration. This finding is also consistent with previously published reports using short duration and mild-moderate intensity of exercise (30). Despite the increase in circulating catecholamine levels and no change in plasma insulin or glucagon concentrations, glucose utilization rose by $70 \%$. This increase in glucose metabolism by exercising muscle was accompanied by a parallel increase in hepatic glucose production, and thus, the plasma glucose concentration remained unchanged (Fig. $1 B$ ).

To assess whether the augmented release of catecholamines during exercise is responsible for the stimulation of hepatic glucose production, we infused propranolol or phentolamine alone or in combination into normal humans. In keeping with earlier studies $(8,9)$, beta adrenergic blockade did not reduce the hepatic response to exercise. Similar results were obtained when alpha blockade was employed, even though circulating insulin rose and the decrease in exercise performance observed in previous studies in the dog (8) was eliminated. Of particular interest, the combined infusion of propranolol and phentolamine was also ineffective in reducing the exercise-mediated increase in hepatic glucose production. It should be emphasized that when combined adrenergic blockade was administered during exercise, plasma concentrations of insulin, glucagon, and free fatty acids were unchanged. Taken together, these observations suggest that in normal man, exercise-induced changes in neither circulating catecholamines nor insulin and glucagon are required for the characteristic rise in hepatic glucose production and peripheral glucose utilization during exercise. Nevertheless, our data do not entirely exclude a role for adrenergic mechanisms in mediating the response of the liver. It is possible that the peripheral infusion of propranolol and phentolamine was insufficient to block direct hepatic stimulation by the adrenergic nervous system. 
Regarding the effects of adrenergic blockade on the hormonal response to exercise, the propranolol infusion accentuated the rise in catecholamines but had no significant effect on changes in circulating insulin and glucagon (Table II). Although it has been reported that propranolol enhances the exercise-induced fall in insulin concentration (29), this has not been a consistent finding $(9,10)$. Similarly, glucagon secretion has been shown either to be unchanged $(9)$ or inhibited $(31,32)$ by propranolol. Our data are also consistent with previous studies demonstrating that alpha blockade increases circulating catecholamines and produces a paradoxical rise in insulin concentration during exercise $(11,29)$. The observation that phentolamine had no effect on circulating glucagon levels during exercise is in agreement with the findings of Galbo et al. $(11,33)$ in normal humans, although variable results have been reported in the rat $(31,34)$.

Although previous studies have shown that beta blockade inhibits lipolysis during exercise $(8,9,10,32,35)$, our data demonstrate only a small, statistically insignificant fall in plasma free fatty acids when propranolol was infused during exercise in normal subjects. Our failure to observe a more pronounced decline in circulating free fatty acids may be related to the relatively mild intensity of the exercise stimulus used in this study. On the other hand, alpha adrenergic blockade (unopposed beta stimulation) produced a significant elevation of plasma free fatty acids both before and after exercise. These findings are consistent with earlier studies (36) and may account for the decrease in glucose uptake observed during phentolamine infusion in the pre-exercise control period.

Whereas plasma glucose levels remained stable in the normal subjects during exercise alone, they gradually declined throughout the 40-min exercise period in the Type I diabetics (Fig. 2 $B$ ). The disparate response of the diabetics can be readily explained when one examines the kinetic data. During the control study, exercise induced a prompt rise in peripheral glucose uptake which was of similar magnitude to that observed in the nondiabetic group. While hepatic glucose production also increased in the diabetics, the increment was insufficient to keep pace with the acceleration of glucose uptake leading to a reduction in circulating glucose concentration. The failure of hepatic glucose production to increase to the same extent as that seen in the controls cannot be attributed to differences in plasma insulin, glucagon, epinephrine, or norepinephrine, which were similar in both groups. Circulating C-peptide concentration did not change significantly during exercise in either diabetics or normals, suggesting that portal levels of insulin were maintained constant in the two groups. Zinman et al. (37) have previously examined the effect of exercise on insulin-infused diabetic subjects and found no change in plasma glucose concentration. However, these authors did not report values for circulating levels of free insulin, C-peptide, glucagon, or catecholamines, and since they did not measure $\mathrm{V}_{2}$ max directly, it is not possible to determine if their experimental conditions were similar to those in the present study (37).

When beta adrenergic blockade with propranolol was produced in the diabetics, the effect on glucose homeostasis in the basal state and during exercise was markedly altered. Prior to the onset of exercise, propranolol infusion resulted in a slight decline in both glucose production and utilization. This suggests that the beta adrenergic system may exert a tonic stimulatory effect on hepatic glucose production and utilization in diabetics. However, since the propranolol infusion was administered through the same intravenous line as the $3-\left[{ }^{3} \mathrm{H}\right]$ glucose, it is possible that this produced a small transient rise in plasma $3-\left[{ }^{3} \mathrm{H}\right]$ glucose counts and thus gave the artifactual impression that $\mathrm{Ra}$ and $\mathrm{Rd}$ were inhibited. This explanation appears unlikely, however, since the decline in $\mathrm{Ra}$ and $\mathrm{Rd}$ was not observed in normals. It is also possible that the decline in $\mathrm{Ra}$ and $\mathrm{Rd}$ observed following the infusion of propranolol (and phentolamine) was due to the release of tritiated glucose counts that accumulated in glycogen during the 3-h period of isotopic equilibration. Although Sacca et al. (19) have previously shown that there is no significant labeling of glycogen when tritiated glucose is infused into normal subjects during the postabsorptive state, this question has not been examined in diabetic individuals.

After the onset of exercise, glucose utilization was significantly enhanced while hepatic glucose production was signifcantly reduced when compared with normal subjects or the exercise control study. This resulted in a precipitous decline in plasma glucose concentration and necessitated the infusion of exogenous glucose to prevent hypoglycemia. The failure of hepatic glucose production to increase normally occurred despite the falling glucose concentration and the fact that plasma insulin and glucagon levels were similar to those observed when diabetics exercised in the absence of propranolol. Furthermore, there was no change in C-peptide levels during exercise in normals or diabetics, indicating that the failure of hepatic glucose production to rise in the diabetics can not be attributed to the inability to suppress portal insulin concentration. These results suggest that the exercise-induced increase in hepatic glucose production in the insulin-dependent diabetic is critically dependent upon beta adrenergic stimulation. This dependency on the beta adrenergic system is clearly different from healthy controls and is consistent with recent observations demonstrating that hepatic glucose production in Type I diabetics is hypersensitive to stimulation by epinephrine $(12,13)$ and more readily suppressed by beta adrenergic blockade (14). Further studies will be needed to delineate under what conditions beta blockade causes hypoglycemia in Type I diabetics and whether selective beta adrenergic blocking agents will exert the same effects as a nonselective beta blocker, such as propranolol.

In addition to inhibiting glucose production, propranolol also caused a significant enhancement in peripheral glucose utilization in the diabetics during exercise. This stimulation of glucose disposal was again in contrast to normal individuals in whom propranolol had no effect on glucose uptake. Since epinephrine is known to inhibit peripheral glucose utilization in normal man $(38,39)$ and diabetics $(12,13)$, it is possible that peripheral tissues, like the liver, are more sensitive to the antagonistic effects of epinephrine. This hypothesis, however, is not supported by previous studies showing a comparable fall 
in glucose clearance in normal and diabetic subjects during epinephrine infusion $(12,13)$. Recent in vitro evidence has also suggested that beta adrenergic blockade may directly enhance glucose uptake in electrically stimulated rat hindquarter muscle (40). Alternatively, the enhancement of glucose utilization may be the result of lower free fatty acid levels in the diabetics. While propranolol produced a small, insignificant decline in free fatty acids in normal subjects, a marked reduction in free fatty acids was observed in diabetics exercising during beta adrenergic blockade. The reduced availability of free fatty acids might be expected to favor the preferential utilization of glucose as a metabolic fuel.

Interestingly, the effects of alpha adrenergic blockade during exercise in the diabetics were the mirror image of those observed with beta adrenergic blockade. The exercise-induced rise in hepatic glucose production was significantly enhanced and glucose utilization tended to be reduced when compared with exercise alone. These changes resulted in a rise, rather than fall, in plasma glucose concentration by the end of the 40-min exercise period. It is unlikely that alterations in circulating insulin or glucagon can account for the effect of phentolamine on glucose kinetics. Insulin and C-peptide levels were quite similar to those observed with exercise alone and the small increase in plasma glucagon with alpha blockade did not reach statistical significance. One could speculate that the increased response of the liver during alpha blockade was the result of the diabetic's greater sensitivity to unopposed beta stimulation $(12,13)$ and that the increased availability of free fatty acids under these conditions diminished glucose utilization by peripheral tissues. It is also possible that the enhanced increase in Ra during the exercise plus phentolamine study was, in part, secondary to an increase in portal venous glucagon concentration that was not reflected by a change in peripheral glucagon levels. However, further studies will be required to clarify the mechanisms responsible for the changes in glucose kinetics induced by alpha blockade.

In summary, our data suggest that the regulation of glucose homeostasis during exercise is more dependent on adrenergic mechanisms in insulin-dependent diabetics than in normal subjects. When beta adrenergic receptors were blocked with propranolol, glucose production and lipolysis were inhibited and glucose utilization was enhanced during exercise in the diabetics, but not in normal subjects. Conversely, when alpha adrenergic receptors were blocked with phentolamine, glucose production and lipolysis were stimulated and glucose utilization was reduced only in the diabetics. It remains to be determined whether the disparate response to adrenergic blockade in the diabetics is mediated by increased sensitivity to catecholamines or other metabolic disturbances associated with the diabetic state. Regardless of the mechanisms involved, our studies indicate that propranolol, a drug commonly used in diabetics, may increase the risk of exercise-induced hypoglycemia.

\section{Acknowledgments}

This study was supported in part by National Institutes of Health grants AM 24092, AM 20495, and Clinical Research Center grant RR 125.
Dr. Koivisto is the recipient of a grant from the Finnish Ministry of Education.

\section{References}

1. Felig, P., and J. Wahren. 1975. Fuel homeostasis in exercise. $N$. Engl. J. Med. 293:1078-1084.

2. Wahren, J., P. Felig, G. Ahlborg, and L. Jorfeldt. 1971. Glucose metabolism during leg exercise in man. J. Clin. Invest. 50:2715-2725.

3. Ahlborg, G., P. Felig, L. Hagenfeldt, R. Hendler, and J. Wahren. 1974. Substrate turnover during prolonged exercise in man. Splanchnic and leg metabolism of glucose, free fatty acids, and amino acids. J. Clin. Invest. 53:1080-1090.

4. Issekutz, B. 1980. The role of hypoinsulinemia in exercise metabolism. Diabetes. 29:629-635.

5. Felig, P., and J. Wahren. 1979. Role of insulin and glucagon in the regulation of hepatic glucose production during exercise. Diabetes. 28(Suppl. 1):71-75.

6. Issekutz, B., and M. Vranic. 1978. Significance of glucagon in the control of glucose production during exercise in dogs. Diabetes. 27(Suppl. 2):454.

7. Muller, W. A., L. Girardier, J. Seydoux, M. Berger, A. E. Renold, and M. Vranic. 1978. Extrapancreatic glucagon and glucagon-like immunoreactivity in depancreatized dogs. J. Clin. Invest. 62:124-132.

8. Issekutz, B. 1979. Energy mobilization in exercising dogs. Diabetes. 28(Suppl. 1):39-44.

9. Galbo, H., J. J. Holst, N. J. Christensen, and J. Hilsted. 1976. Glucagon and plasma catecholamines during beta-receptor blockade in exercising man. J. Appl. Physiol. 40:855-863.

10. Christensen, N. J., H. Galbo, J. F. Hansen, B. Hesse, E. A. Richter, and J. Trap-Jensen. 1979. Catecholamines and exercise. Diabetes. 28(Suppl. 1):58-62.

11. Galbo, H., N. J. Christensen, and J. J. Holst. 1977. Catecholamines and pancreatic hormones during autonomic blockade in exercising man. Acta Physiol. Scand. 101:428-437.

12. Sherwin, R. S., H. Shamoon, R. Hendler, L. Sacca, N. Eigler, and M. Walesky. 1980. Epinephrine and the regulation of glucose metabolism: effect of diabetes and hormonal interactions. Metab. Clin. Exp. 29:1146-1154.

13. Shamoon, H., R. Hendler, and R. S. Sherwin. 1980. Altered responsiveness to cortisol, epinephrine, and glucagon in insulin-infused juvenile-onset diabetics. Diabetes. 29:284-291.

14. Shamoon, H., and R. S. Sherwin. 1980. Disparate effect of betablockade on the hepatic response to epinephrine in normal and diabetic man. Clin. Res. 28:405A.

15. Kotler, M. N., L. Berman, and A. H. Rubinstein. 1966. Hypoglycemia precipitated by propranolol. Lancet. II:1389-1390.

16. Skinner, D. J., and R. I. Misbin. 1975. Uses of propranolol. $N$. Eng. J. Med. 293:1205.

17. Lager, I., G. Blohme, and U. Smith. 1979. Effect of cardioselective and nonselective beta-blockade on the hypoglycaemic response in insulindependent diabetics. Lancet. I:458-462.

18. Uusitupa, M., A. Aro, and M. Pietikainen. 1980. Severe hypoglycemia caused by physical strain and pindolol therapy. Ann. Clin. Res. 12:25-27.

19. Sacca, L., C. Vigorito, M. Cicala, B. Ungaro, and R. S. Sherwin. 1982. Mechanisms of epinephrine-induced glucose intolerance in normal humans. J. Clin. Invest. 69:284-293.

20. Steele, R. 1959. Influences of glucose loading and of injected insulin on hepatic glucose output. Ann. NY Acad. Sci. 82:420-430. 
21. Altszuler, N., A. Barkai, A. Bjerknes, B. Gottlieb, and R. Steele. 1975. Glucose turnover values in the dog obtained with various species of labeled glucose. Am. J. Physiol. 229:1662-1667.

22. Rosselin, G., R. Assan, R. S. Yalow, and S. A. Berson. 1966. Separation of antibody-bound and unbound peptide hormones labeled with iodine- 131 by talcum powder and precipitated silica. Nature (Lond.). 212:355-357.

23. Kuzuya, H., P. M. Blix, D. L. Horwitz, D. F. Steiner, and A. H. Rubinstein. 1977. Determination of free and total insulin and C-peptide in insulin treated diabetics. Diabetes. 26:22-29.

24. DeFronzo, R. A., R. Hendler, and D. Simonson. 1982. Insulin resistance is a prominent feature of insulin-dependent diabetes. Diabetes. 31:795-801.

25. Aguilar-Parada, E., A. M. Eisentraut, and R. H. Unger. 1969. Pancreatic glucagon secretion in normal and diabetic subjects. Am. J. Med. Sci. 257:415-419.

26. Dole, V. P. 1956. A relation between non-esterified fatty acids in plasma and the metabolism of glucose. J. Clin. Invest. 35:150-154.

27. Novak, M. 1965. Colorimetric ultramicro method for the determination of free fatty acids. J. Lipid. Res. 6:431-433.

28. Galbo, H., E. A. Richter, J. Hilsted, J. J. Holst, N. J. Christensen, and J. Henricksson. 1977. Hormonal regulation during prolonged exercise. Ann. NY Acad. Sci. 301:72-80.

29. Robinson, R. P., and D. Porte. 1973. Adrenergic modulation of basal insulin secretion in man. Diabetes. 22:1-8.

30. Galbo, H., N. J. Christensen, K. J. Mikines, B. Sonne, J. Hilsted, C. Hagen, and J. Fahrenkrug. 1981. The effect of fasting on the hormonal response to graded exercise. J. Clin. Endocrinol. Metab. 52:1106-1112.

31. Luyckx, A. S., and P. J. Lefebvre. 1974. Mechanisms involved in the exercise-induced increase in glucagon secretion in rats. Diabetes. 23:81-93.

32. Day, J. L. 1975. The metabolic consequences of adrenergic blockade: a review. Metab. Clin. Exp. 24:987-996.

33. Galbo, H., N. J. Christensen, and J. J. Holst. 1976. The role of the autonomic nervous system in the control of glucagon and insulin responses to prolonged exercise in man. Acta Physiol. Scand. Suppl. 440:175. (Abstr.)

34. Harvey, W. D., G. R. Faloona, and R. H. Unger. 1974. The effect of adrenergic blockade on exercise induced hyperglucagonemia. Endocrinology. 94:1254-1258.

35. Allison, S. P., M. J. Chamberlain, J. E. Miller, R. Ferguson, A. P. Gillett, B. V. Bemand, and R. A. Saunders. 1969. Effects of propranolol on blood sugar, insulin, and free fatty acids. Diabetologia. 5:339-342.

36. Hartley, L. H., J. W. Mason, R. P. Hogan, L. G. Jones, T. A. Kotchen, E. H. Mougey, F. E. Wherry, L. L. Pennington, and P. T. Ricketts. 1972. Multiple hormonal responses to graded exercise in relation to physical training. J. Appl. Physiol. 33:602-606.

37. Zinman, B., M. Vranic, A. M. Albisser, B. S. Leibel, and E. B. Marliss. 1979. The role of insulin in the metabolic response to exercise in man. Diabetes. 28(Suppl. 1):76-81.

38. Deibert, D. C., and R. A. DeFronzo. 1980. Epinephrine-induced insulin resistance in man. J. Clin. Invest. 65:717-721.

39. Rizza, R. A., P. E. Cryer, M. W. Haymond, and J. E. Gerich. 1980. Adrenergic mechanisms for the effects of epinephrine on glucose production and clearance in man. J. Clin. Invest. 65:682-689.

40. Richter, E. A., N. B. Ruderman, and H. Galbo. 1982. Alpha and beta adrenergic effects on metabolism in contracting, perfused muscle. Acta Physiol. Scand. 116:215-222. 